Article

\title{
Efficient Consecutive Synthesis of Ethyl-2-(4-Aminophenoxy) Acetate, a Precursor for Dual GK and PPAR $\gamma$ Activators, X-ray Structure, Hirshfeld Analysis, and DFT Studies
}

\author{
Mezna Saleh Altowyan ${ }^{1}$, Saied M. Soliman ${ }^{2}$, Magda M. F. Ismail ${ }^{3}$, Matti Haukka ${ }^{4}$ (D), Assem Barakat ${ }^{5, *(\mathbb{D})}$ \\ and Mohammed Salah Ayoup 2,*
}

1 Department of Chemistry, College of Science, Princess Nourah bint Abdulrahman University, P.O. Box 84428, Riyadh 11671, Saudi Arabia; msaltowyan@pnu.edu.sa

2 Department of Chemistry, Faculty of Science, Alexandria University, P.O. Box 426, Alexandria 21321, Egypt; saeed.soliman@alexu.edu.eg

3 Department of Pharmaceutical Medicinal Chemistry, Faculty of Pharmacy (Girls), Al-Azhar University, Cairo 11651, Egypt; magdaismail@azhar.edu.eg

4 Department of Chemistry, University of Jyväskylä, P.O. Box 35, FI-40014 Jyväskylä, Finland; matti.o.haukka@jyu.fi

5 Department of Chemistry, College of Science, King Saud University, P.O. Box 2455, Riyadh 11451, Saudi Arabia

* Correspondence: ambarakat@ksu.edu.sa (A.B.); mohamed.salah@alexu.edu.eg (M.S.A.); Tel.: +96-61-1467-5901 (A.B.); Fax: +96-61-1467-5992 (A.B.)

Citation: Altowyan, M.S.; Soliman, S.M.; Ismail, M.M.F.; Haukka, M.; Barakat, A.; Ayoup, M.S. Efficient Consecutive Synthesis of Ethyl-2-(4-Aminophenoxy) Acetate, a Precursor for Dual GK and PPAR $\gamma$ Activators, X-ray Structure, Hirshfeld Analysis, and DFT Studies. Crystals 2022, 12, 227. https://doi.org/ $10.3390 /$ cryst12020227

Academic Editors: Helmut Cölfen and Jesús Sanmartín-Matalobos

Received: 23 December 2021

Accepted: 1 February 2022

Published: 5 February 2022

Publisher's Note: MDPI stays neutral with regard to jurisdictional claims in published maps and institutional affiliations.

Copyright: (C) 2022 by the authors. Licensee MDPI, Basel, Switzerland. This article is an open access article distributed under the terms and conditions of the Creative Commons Attribution (CC BY) license (https:// creativecommons.org/licenses/by/ $4.0 /)$.

\begin{abstract}
Herein, we report a facile synthesis of ethyl-2-(4-aminophenoxy)acetate 4 as a building synthon for novel dual hypoglycemic agents. This building template was synthesized by alkylation of 4-nitrophenol with ethyl bromo-acetate followed by selective reduction of the nitro group. This reduction methoddoes not require nascent hydrogen or any reaction complexity; it goes easily via consecutive reaction in $\mathrm{NH}_{4} \mathrm{Cl} / \mathrm{Fe}$ to yield our target synthon as very pure crystals. This product was characterized by ${ }^{1} \mathrm{HNMR},{ }^{13} \mathrm{CNMR}$, COSY, NOESY NMR spectroscopy, and elemental analysis. Additionally, its structure was studied and approved by $\mathrm{X}$-ray single crystal structure determination. The unit cell parameters are $a=8.2104(6) \AA, b=10.3625(9) \AA, c=11.9562(9) \AA, \alpha=101.787(7)$, $\beta=91.849(6)$, and $\gamma=102.755(7)^{\circ}$, indicating that 4 was crystallized in the triclinic crystal system. The cooperative non-covalent interactions are also discussed with the aid of Hirshfeld surface analysis. The $\mathrm{H} \ldots \mathrm{H}, \mathrm{H} \ldots \mathrm{C}$, and $\mathrm{O} \ldots \mathrm{H}$ interactions have a major contribution in the molecular packing of 4. Moreover, different quantum chemical parameters were computed and discussed based on DFT calculations. The experimental UV/Vis spectra showed two bands at 299 and $234 \mathrm{~nm}$, which were calculated using the TD-DFT method at $286(\mathrm{f}=0.068)$ and $226 \mathrm{~nm}(\mathrm{f}=0.294)$, respectively. These bands were assigned to $\mathrm{HOMO} \rightarrow \mathrm{LUMO}(95 \%)$ and $\mathrm{HOMO} \rightarrow \mathrm{LUMO}+2(86 \%)$ transitions, respectively.
\end{abstract}

Keywords: aminophenoxy; consecutive reaction; hypoglycemic; X-ray; Hirshfeld analysis

\section{Introduction}

The more rampant type 2 diabetes (T2D) is a category of metabolic diseases distinguished by hyperglycemia resulting from a flaw in insulin secretion, insulin action, or both. The chronic hyperglycemia of diabetes is affiliated with long-term impairment, dysfunction, and collapse of many organs, particularly the kidneys, heart, eyes, nerves, and blood vessels [1,2].

Glucokinase (GK), a glucose-phosphorylating enzyme, is predominantly expressed in the liver and pancreatic b-cells. This glucokinase enzyme are considered as a prospective therapeutic target for T2D [3,4]. Compound I reported by Prosidion/OSI is an activator of GK and not only boosts glycogen synthesis, but also escalates insulin secretion from 
pancreatic b-cells. Consequently, the progress of GK sensitizer to reduce blood glucose and normalize insulin secretion is an encouraging area of ongoing research for treating T2D.Compound II reported by Sumitomo, a Peroxisome proliferator-activator PPAR $\gamma$, ameliorates insulin activity in the muscle and liver, which puts forward an auspicious remedial perspective for metabolic syndrome [5,6] (Figure 1).<smiles>Cc1ccc(C(=O)c2cccn2C/C=C/c2cccc(OCC(=O)O)c2)cc1</smiles>

Figure 1. Reported antidiabetic agents.

As the single drug available in the market just addresses the specific platform of T2D and can persuade drug resistance, it is necessary to advance multiple-target hypoglycemic drugs with a more prevalent medicinal effect. In this regard, the assemblage of ligand-based pharmacophores (colored blue) was accomplished (Figure 2) [6]. Based upon this template, a series of phenyl-urea linked to modifiable nitrogen heteroaromatic groups were evaluated for their ability to activate both GK and PPAR gamma. Interestingly, compounds III-V showed high capacity to activate both GK and PPAR $\gamma$ concurrently [6].

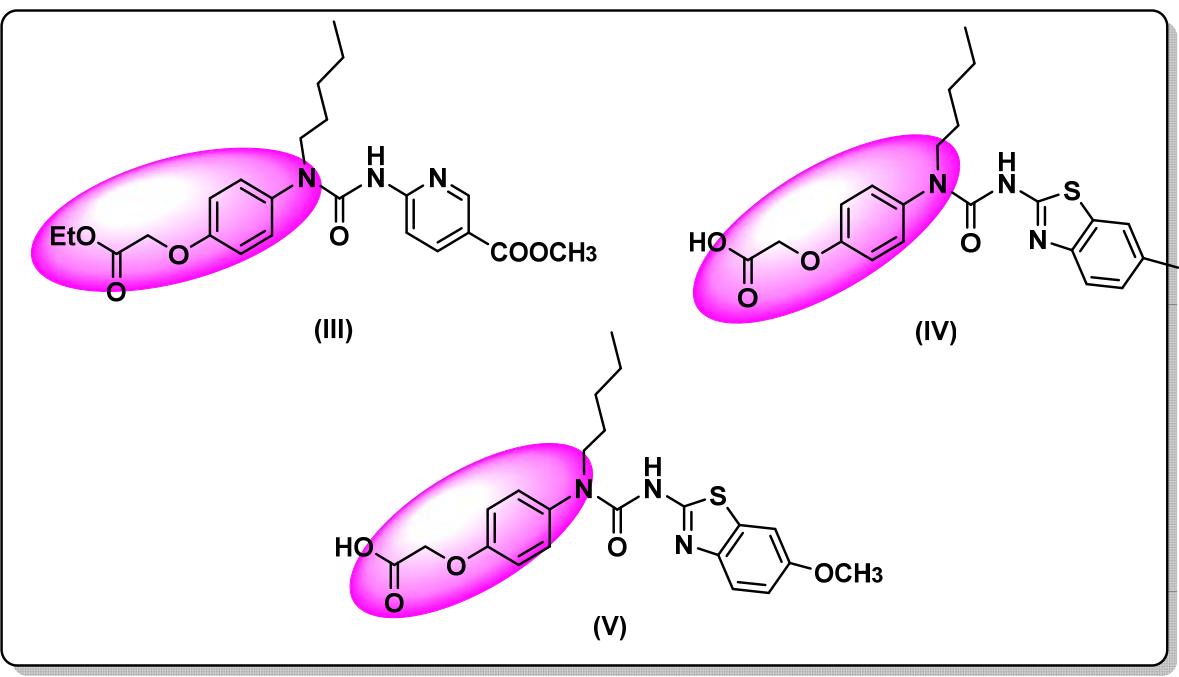

Figure 2. Reported dual activators of GK and PPAR.

Over the past decade, the usage of active pharmaceutical ingredients (APIs) has acquired built-up interest thanks to their extensive practice in medicinal chemistry and drug discovery [7-9]. Based on previous findings, it was of interest to prepare ethyl 2(4-aminophenoxy) acetate, a building synthon for multiple-target hypoglycemic action (c.f. highlighted in Figure 2). This newly synthesized building synthon was characterized using the NMR spectral technique and its structure was confirmed by single-crystal X-ray diffraction. The cooperative non-covalent interactions are discussed based on Hirshfeld surface analysis. Moreover, quantum chemical descriptors were computed by the B3LYP method with 6-31G $(\mathrm{d}, \mathrm{p})$ basis sets implemented in Gaussian 09 using the crystallographic information files (cif) obtained from the $\mathrm{X}$-ray diffraction measurement. 


\section{Materials and Methods}

\subsection{Materials and Equipments}

The details regarding materials, glassware, and instrumentations are presented in the Supplementary Materials.

\subsection{Synthesis of Ethyl-2-(4-Aminophenoxy) Acetate (4)}

A mixture of p-nitrophenol $(1.39 \mathrm{~g}, 0.01 \mathrm{~mol})$ in dry acetone $(20 \mathrm{~mL})$ and anhydrousK ${ }_{2} \mathrm{CO}_{3}$ $(2.76 \mathrm{~g}, 0.02 \mathrm{~mol})$ was refluxed for $20 \mathrm{~min}$ with stirring. Then, ethyl 2-bromoacetate $(1.7 \mathrm{~g}$, $0.01 \mathrm{~mol})$ and potassium iodide $(10 \mathrm{mg})$ were added, the mixture was refluxed for $8 \mathrm{~h}$, and the reaction was monitored by TLC. After completion of the reaction, heating was stopped and the mixture was filtered on hot and washed with acetone. Then, the solvent was evaporated under reduced pressure at $40{ }^{\circ} \mathrm{C}$, and the pale yellow solid of ethyl 2-(4nitrophenoxy) acetate was used directly for the next step, where ammonium chloride (1.6 g, $0.03 \mathrm{~mol})$ in a solution of mixture ethanol and distilled water $(30 \mathrm{~mL}, 1: 1)$ was added to the crude product. The mixture was refluxed for $30 \mathrm{~min}$ with stirring, the magnetic bar was removed, and then Fe powder $(1.68 \mathrm{~g}, 0.03 \mathrm{~mol})$ was added separately and the mixture was refluxed for a further $4 \mathrm{~h}$. The mixture was filtered on hot and washed with hot water. Then, the filtrate was left to cool to room temperature was then extracted by ethyl acetate $(3 \times 30)$. The organic layers were then collected and dried over anhydrous sodium sulfate, and filtered. The filtrate was left for 1 week at room temperature to give the reddish brown crystals of ethyl 2-(4-aminophenoxy)acetate (4), (1.22 gm, 62\%); m.p. $=56-58{ }^{\circ} \mathrm{C} ;{ }^{1} \mathrm{H} \mathrm{NMR}$ $\left(500 \mathrm{MHz}, \mathrm{DMSO}-d_{6}\right) \delta_{H}: 6.62(\mathrm{~d}, J=9.0 \mathrm{~Hz}, 2 \mathrm{H}, \mathrm{Ar}-\mathrm{H}), 6.47(\mathrm{~d}, J=9.0 \mathrm{~Hz}, 2 \mathrm{H}, \mathrm{Ar}-\mathrm{H}), 4.65(\mathrm{~s}$, $\left.2 \mathrm{H}, \mathrm{NH}_{2}\right), 4.55\left(\mathrm{~s}, 2 \mathrm{H}, \mathrm{ArO}-\mathrm{CH}_{2}-\mathrm{CO}\right), 4.12\left(\mathrm{q}, J=7.0 \mathrm{~Hz}, 2 \mathrm{H}, \mathrm{O}-\mathrm{CH}_{2} \mathrm{CH}_{3}\right), 1.18(\mathrm{t}, J=7.0 \mathrm{~Hz}$, $3 \mathrm{H}, \mathrm{O}-\mathrm{CH}_{2} \mathrm{CH}_{3}$ ) (Supplementary Materials Figure S1); ${ }^{13} \mathrm{C}$ NMR (125 MHz, DMSO- $\left.d_{6}\right) \delta_{C}$ : 169.3, 148.9, 143.1, 115.5, 114.7, 65.6, 60.4, 14.1 (Supplementary Materials Figure S2); Anal. Calcd for $\mathrm{C}_{10} \mathrm{H}_{13} \mathrm{NO}_{3}$ : C 61.53, $\mathrm{H}$ 6.71, N 7.18; found C 61.50, H 6.72, N 7.21.

\subsection{X-ray Structure Determination}

The crystal structure measurement details are summarized in Table S1 (Supplementary Materials) and further experimental details are depicted in the Supplementary Materials [10-13].

\subsection{Computational Methods}

The computational details for the Hirshfeld analysis and [14] DFT calculations are presented in the Supplementary Materials [15-17].

\section{Results and Discussion}

\subsection{Chemistry}

Reduction of nitro aromatic compounds could be achieved by miscellaneous reagents differing in efficiency, selectivity and safety. Herein, we highlighted the consecutive synthesis of ethyl-2-(4-aminophenoxy)acetate (4). The direct alkylation of $p$-nitrophenol 1 using ethyl bromoacetate 2 in the presence of potassium carbonate and traces of potassium iodide afforded ethyl $p$-nitrophenoxy acetate 3 . Then, the reduction of 3 without separation or further purification accomplished by adding $\mathrm{NH}_{4} \mathrm{Cl} / \mathrm{Fe}$ in a mixture of ethanol/water and then reflux for $4 \mathrm{~h}$, hot filtration, followed by extraction using EtOAc $(3 \times 30)$. After which it was left to stand to afford the reddish-brown crystals of (4) (Scheme 1). Reduction of 3 to the ethyl 2-(4-aminophenoxy) acetate (4) using $\mathrm{NH}_{4} \mathrm{Cl} / \mathrm{Fe}$ is safer as well as cheaper than the previously reported reaction using $\left(\mathrm{H}_{2}\right.$ and $\left.\mathrm{Pd} / \mathrm{C} 10 \%\right)$ [18]. The structure of (4) was confirmed by X-ray single crystal structure, elemental analysis, and NMR spectra. The ${ }^{1} \mathrm{HNMR}$ showed significant signals at $\delta_{H}: 6.62$ and6.47 ppm, revealed to two doublets sets of four protons for $\mathrm{p}$-substituted aromatic system, in addition to three sets of signals at $4.65,4.55$, and 4.12 , representing three types of protons equivalent to $\mathrm{NH}_{2}, \mathrm{ArO}-\mathrm{CH}_{2}$ and $\mathrm{O}-\mathrm{CH}_{2} \mathrm{CH}_{3}$ respectively. Moreover, ${ }^{13} \mathrm{C}$ NMR exhibited one type of carbonyl carbon at $\delta_{C}: 169.3$ and three isolated signals at $\delta_{C} 65.6,60.4$, and $14.1 \mathrm{ppm}$ corresponded to 
two $\mathrm{CH}_{2}$ carbons and one $\mathrm{CH}_{3}$. From COSY NMR spectra, it is clearly shown that protons type $1\left(\mathrm{CH}_{3}\right)$ and type $2\left(\mathrm{CH}_{2}\right)$ are attached to adjacent carbon and have a clear correlation. Similarly, aromatic proton 5 and 6 are also adjacent to each other, which means both type of protons are attached to adjacent aromatic carbon. Protons type 3 and 4 are not associated to any other protons (see Figure S3A-D; Supplementary Data). NOESY NMR spectra show weak NOE correlations (see Supplementary Materials Figure S4A,B).

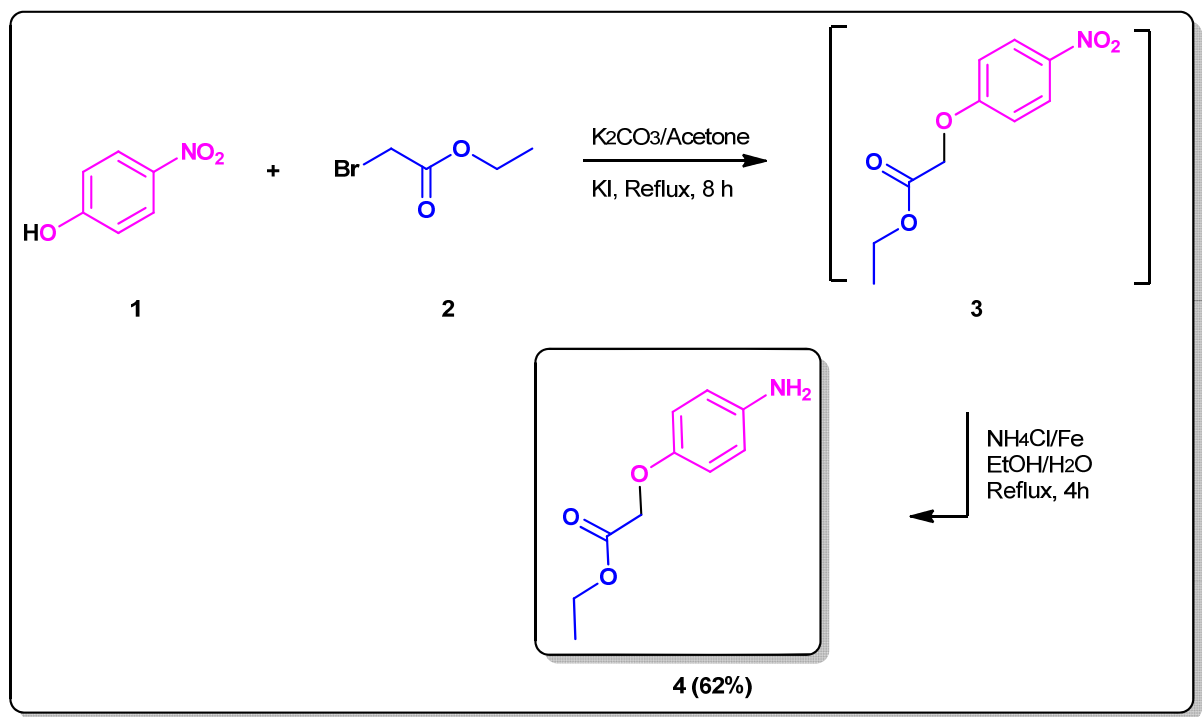

Scheme 1. Synthesis of ethyl 2-(4-aminophenoxy) acetate (4).

\subsection{X-ray Structure}

The reported X-ray structure of 4 showed good agreement with its spectral characterizations (Figure 3A). It crystallized in the triclinic crystal system and the $P-1$ space group with $Z=2$ and two molecular units as asymmetric formula. The unit cell parameters are $a=8.2104(6) \AA, b=10.3625(9) \AA, c=11.9562(9) \AA, \alpha=101.787(7), \beta=91.849(6)$, $\gamma=102.755(7)^{\circ}$, and $V=968.02(14) \AA^{3}$. Some selected geometric parameters are listed in Table 1.

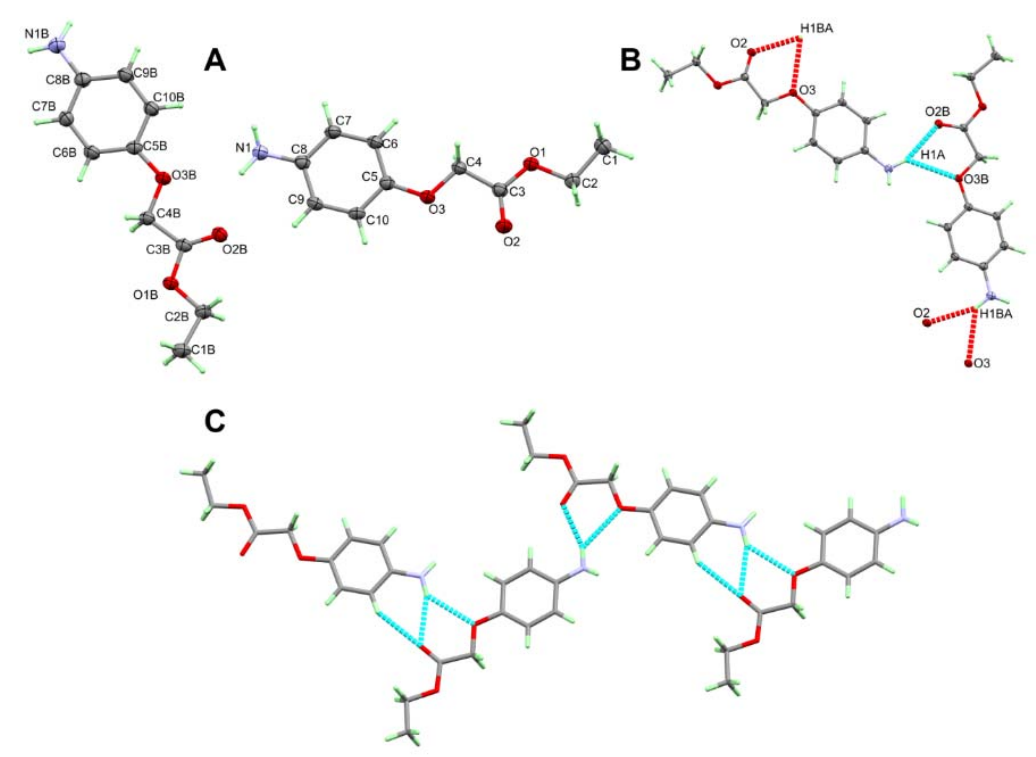

Figure 3. X-ray structure (A), hydrogen bonds (B), and part of packing scheme (C) of 4 . 
Table 1. Selected geometric parameters $\left[\AA{ }^{\circ}\right]$ for 4 .

\begin{tabular}{cccc}
\hline Atoms & Distance & Atoms & Distance \\
\hline O1-C3 & $1.3301(15)$ & O1B-C3B & $1.3381(14)$ \\
O1-C2 & $1.4534(16)$ & O1B-C2B & $1.4566(15)$ \\
O2-C3 & $1.2037(16)$ & O2B-C3B & $1.2052(16)$ \\
O3-C5 & $1.3822(15)$ & O3B-C5B & $1.3801(15)$ \\
O3-C4 & $1.4123(15)$ & O3B-C4B & $1.4143(14)$ \\
N1-C8 & $1.3961(17)$ & N1B-C8B & $1.4050(17)$ \\
\hline Atoms & Angle & Atoms & Angle \\
C3-O1-C2 & $115.59(10)$ & O3-C4-C3 & $106.98(10)$ \\
C5-O3-C4 & $117.06(9)$ & O3-C5-C6 & $125.35(11)$ \\
O1-C2-C1 & $107.47(10)$ & O3-C5-C10 & $115.33(10)$ \\
O2-C3-O1 & $124.80(12)$ & C6-C5-C10 & $119.32(11)$ \\
O2-C3-C4 & $125.26(12)$ & C5-C6-C7 & $119.82(11)$ \\
O1-C3-C4 & $109.94(10)$ & C8-C7-C6 & $121.22(11)$ \\
\hline
\end{tabular}

The molecules of 4 are packed in the crystal by $\mathrm{N}-\mathrm{H} \cdots \mathrm{O}$ hydrogen bond contacts shown in Figure 3B. The shortest donor-acceptor distances are 3.1130(14) and 3.1706(16) $\mathrm{A}$, corresponding to N1-H1A $\cdots \mathrm{O} 2 \mathrm{~B}$ and N1B-H1BA $\cdots \mathrm{O} 2 \# 1$ hydrogen bond contacts, respectively (Table 2). The packing of the molecular units is shown in Figure 3C.

Table 2. Hydrogen bonds for $4\left[\AA\right.$ and $\left.^{\circ}\right]$.

\begin{tabular}{|c|c|c|c|c|}
\hline D-H $\cdots A$ & $d(D-H)$ & $d(H \cdots A)$ & $d(D \cdots A)$ & $<$ (DHA) \\
\hline N1-H1A …2ㅡ & $0.930(19)$ & $2.234(19)$ & $3.1130(14)$ & $157.2(16)$ \\
\hline N1-H1A …그 & $0.930(19)$ & $2.549(19)$ & $3.2622(15)$ & $133.8(14)$ \\
\hline N1B-H1BA …O2\#1 & $0.89(2)$ & $2.32(2)$ & $3.1706(16)$ & 157.9(17) \\
\hline N1B-H1BA $\cdots$ O3\#1 & $0.89(2)$ & $2.55(2)$ & $3.2487(14)$ & $135.7(16)$ \\
\hline
\end{tabular}

Symm. Code: $\# 1 \mathrm{x}+1, \mathrm{y}, \mathrm{z}-1$.

\subsection{Hirshfeld Surface Analysis}

The $d_{\text {norm }}$ is defined by Equation (1), where the terms $d_{e}$ and $d_{i}$ represent the distances from a point at the map surface to the nearest atom internal $\left(d_{i}\right)$ or external $\left(d_{e}\right)$ to the map. $r_{i}^{v d W}$ and $r_{e}^{v d W}$ are the van der Waals radii of the interacting atoms, respectively $[19,20]$.

$$
d_{\text {norm }}=\frac{d_{i}-r_{i}^{v d W}}{r_{i}^{v d W}}+\frac{d_{e}-r_{e}^{v d W}}{r_{e}^{v d W}}
$$

Decomposition of the different intermolecular contacts in $\mathbf{4}$ was performed using Hirshfeld calculations (Figure 4). All possible contacts among molecular units in the crystal of 4 are presented in Figure 5. The total in the fingerprint plot represents the whole intermolecular contacts occurring in the crystal. Hence, decomposition of this plot gave the percentages of each contact. Moreover, the sharp spike in this plot refers to interactions occurring at short contact distances, and those are considered strong [19-21]. Analysis of these interactions using fingerprint plot and $d_{\text {norm }}$ maps is given in Figure 6. The major contacts are $\mathrm{H} \cdots \mathrm{H}, \mathrm{H} \cdots \mathrm{C}$ and $\mathrm{O} \cdots \mathrm{H}$ interactions. Their percentages are $52.7,18.0$, and $22.2 \%$ in molecule $\mathbf{A}$ and $54.3,13.8$, and $22.3 \%$ in molecule $\mathbf{B}$, respectively. In addition, some significant short $\mathrm{N} \cdots \mathrm{H}$ contacts were observed. Their percentages are $3.5 \%$ and $3.2 \%$ in molecules $\mathbf{A}$ and $\mathbf{B}$, respectively. Moreover, the $\mathrm{O} \cdots \mathrm{H}$ and $\mathrm{H} \cdots \mathrm{C}(\mathrm{C}-\mathrm{H} \cdots \pi)$ interactions are generally short and appeared as red regions in $\mathrm{d}_{\text {norm }}$ map. Details regarding the important short contacts and the corresponding interaction distances based on Hirshfeld calculations are listed in Table 3. 

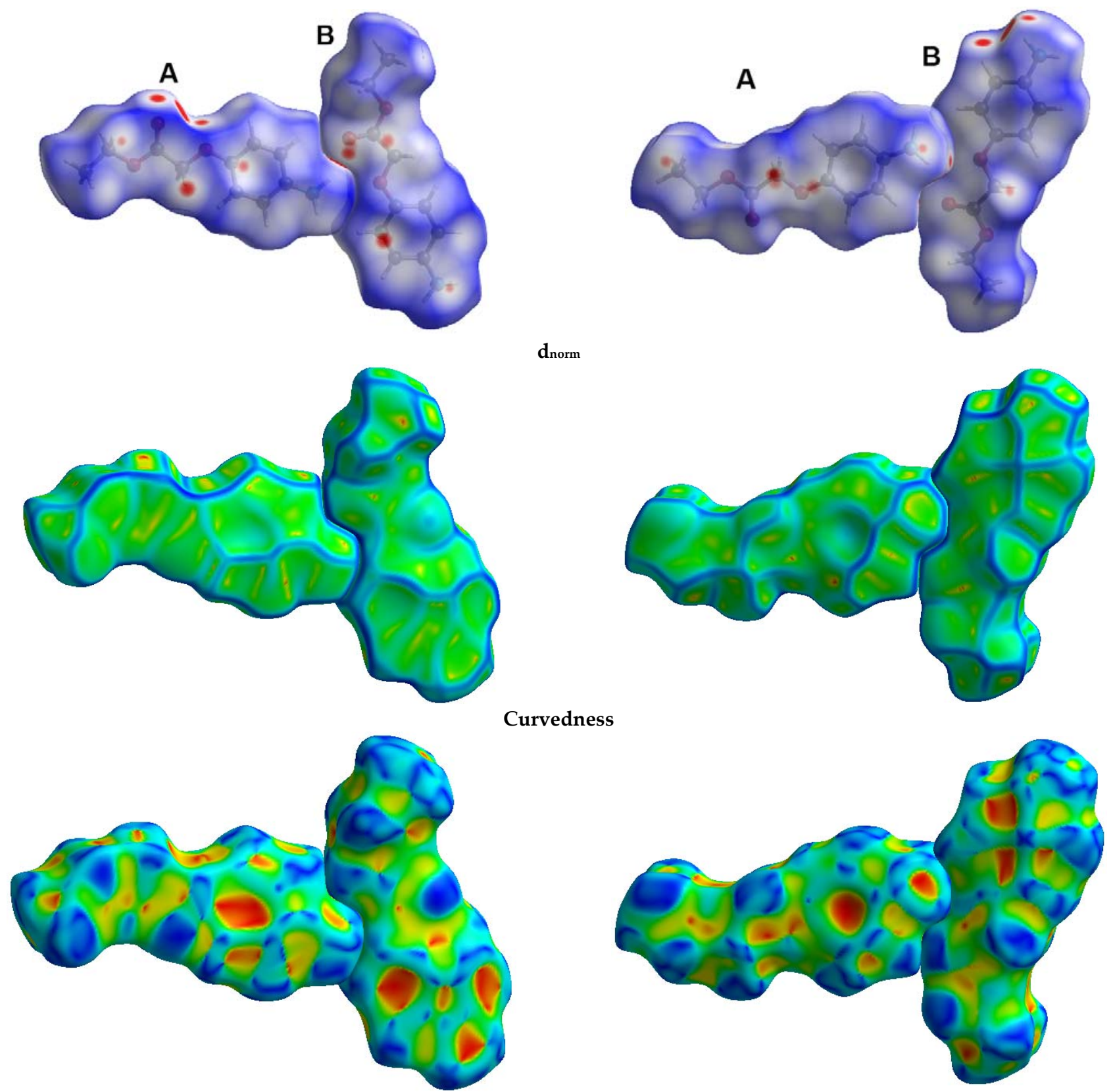

Shape index

Figure 4. Hirshfeld surfaces of 4. Molecule B has letter B in atom numbering, while A does not.

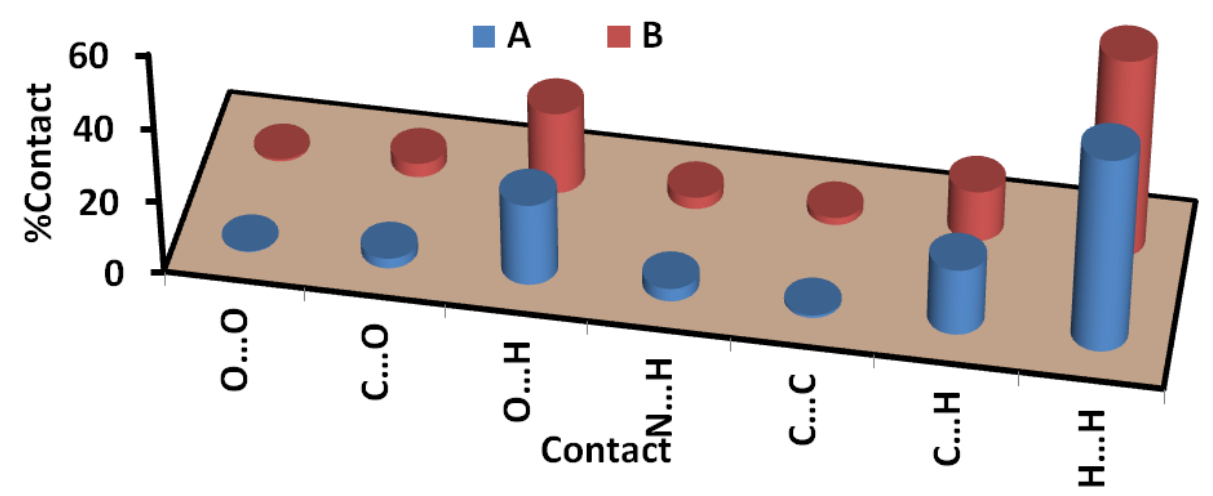

Figure 5. Intermolecular contacts in 4. 


\section{Molecule A}
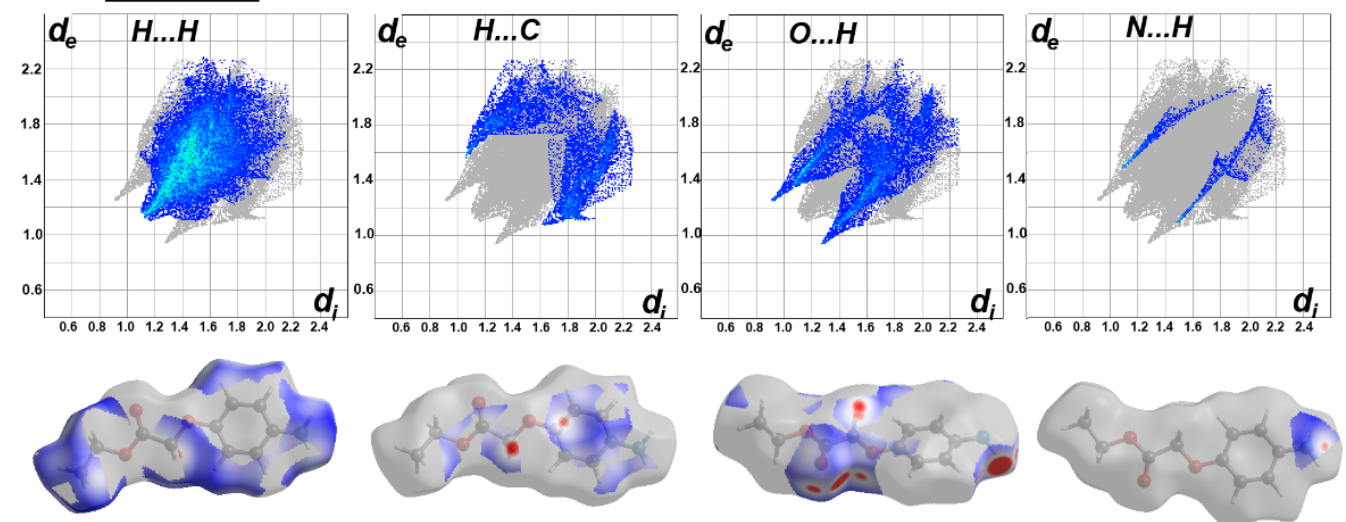

Molecule B
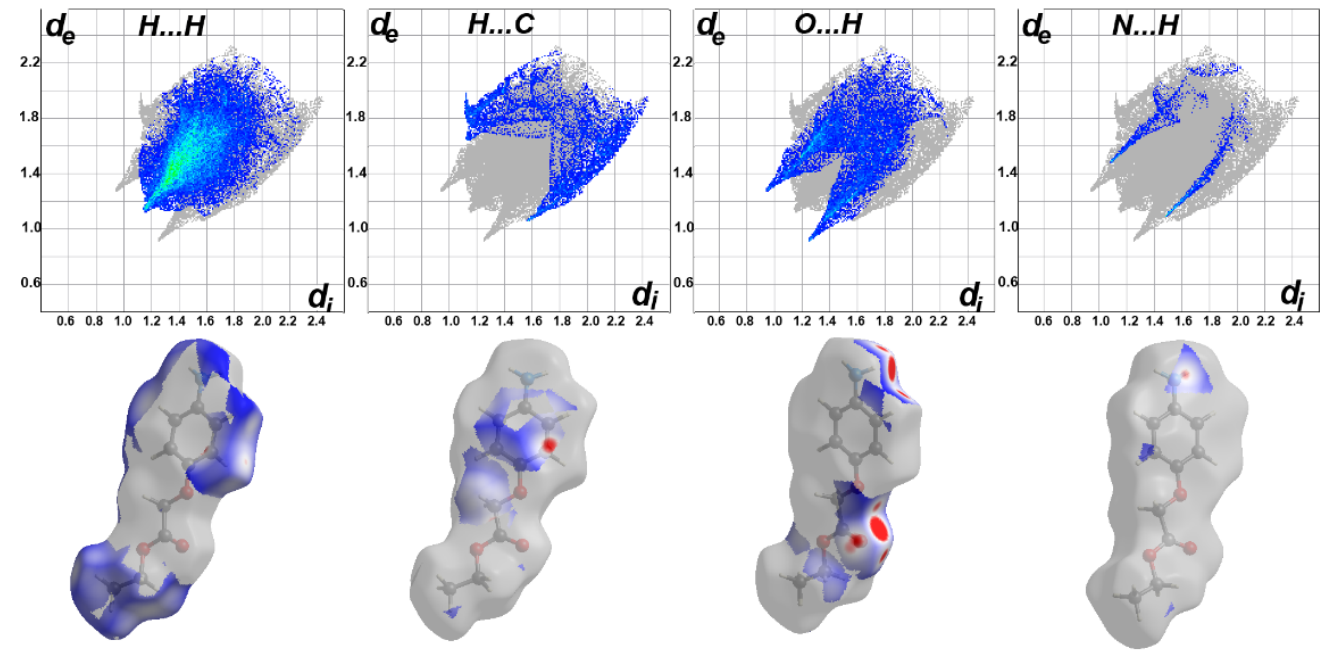

Figure 6. Decomposed fingerprint plots and $d_{\text {norm }}$ maps for 4 .

Table 3. Contact distances of the most important intermolecular interactions.

\begin{tabular}{cccc}
\hline Contact & Distance & Contact & Distance \\
\hline O3B .. H1A & 2.494 & O1 . H H17 & 2.555 \\
O2B . H1A & 2.163 & N1B . H2B & 2.572 \\
O2 . H9 & 2.42 & N1 . H4B & 2.573 \\
O2B . H4B & 2.459 & C10B . H4A & 2.627 \\
O3 $\ldots$ H1BA & 2.467 & C5 . H1C & 2.7 \\
O2 .. H1BA & 2.219 & H1D . H9B & 2.279 \\
O2 .. H9B & 2.418 & H1C . H10B & 2.456 \\
\hline
\end{tabular}

Significant contacts appeared as red spots while weak less significant contacts appeared as blue and white regions. Red, white, and blue indicated a shorter, equal, and longer distance than van der Waals radii sum of the interacting elements. On the other hand, the curvedness map gave a great idea about the flatness of the molecular surface. The large green area indicates a relatively flat surface, while the dark blue edges are for large positive curvature [21]. On the other hand, shape index gave an indication of the presence of complementary hollows (red) and bumps (blue) where two molecular surfaces touch one another. These characteristics are important for deciding the presence of $\pi-\pi$ stacking interactions, which is absent in the studied system.

\subsection{DFT Studies}

The X-ray geometry of 4 was optimized using the B3LYP/6-31G(d,p) method and the resulting minimum energy structure, which has no any imaginary frequency, is shown in 
Figure 7 (upper part).For structure comparison, the experimental and calculated structures are overlaid (Figure 7; upper part). As can be seen, there is very good structure matching between the optimized and experimental structures. Some very small deviations could be attributed to the crystal packing effects (Supplementary Materials Table S2). Moreover, the optimized and experimental parameters correlated very well and the correlation coefficients are close to 1 (Figure 8).

a

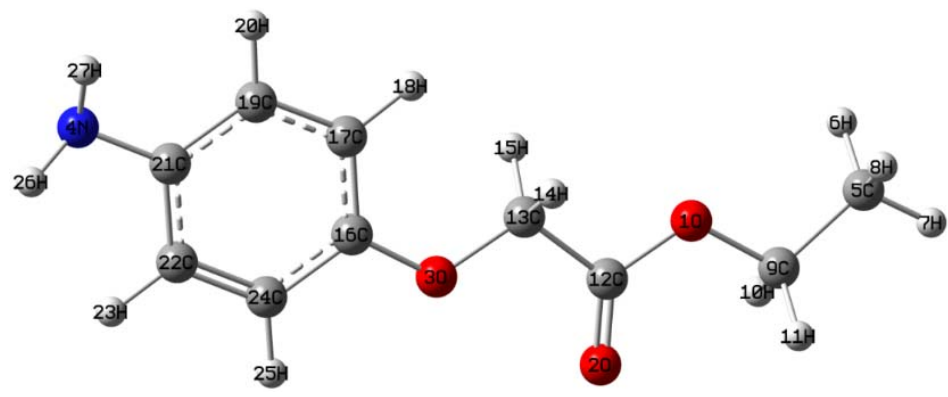

b

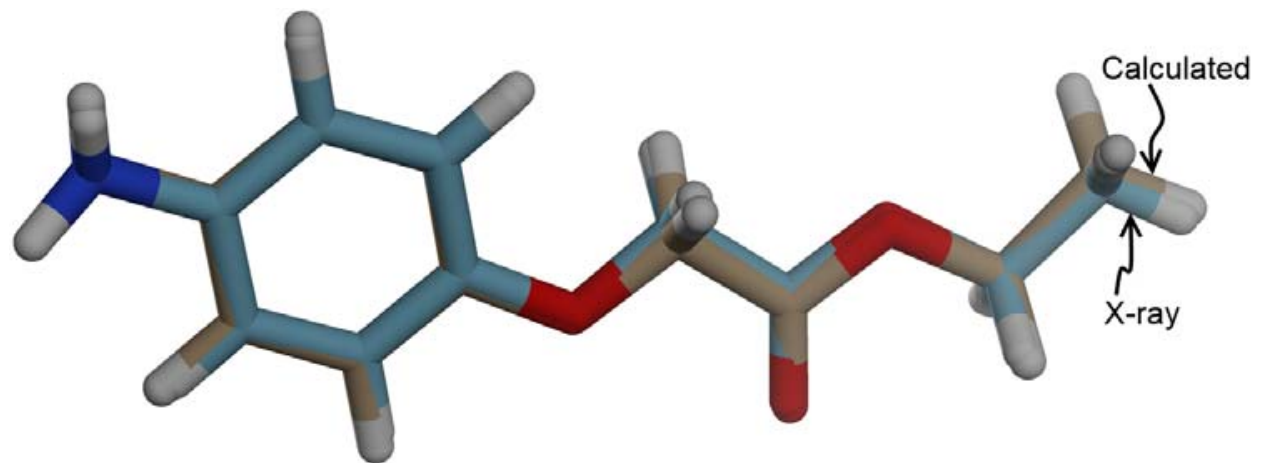

Figure 7. The optimized geometry (a) and overlay of the optimized with experimental structures, (b) for 4.
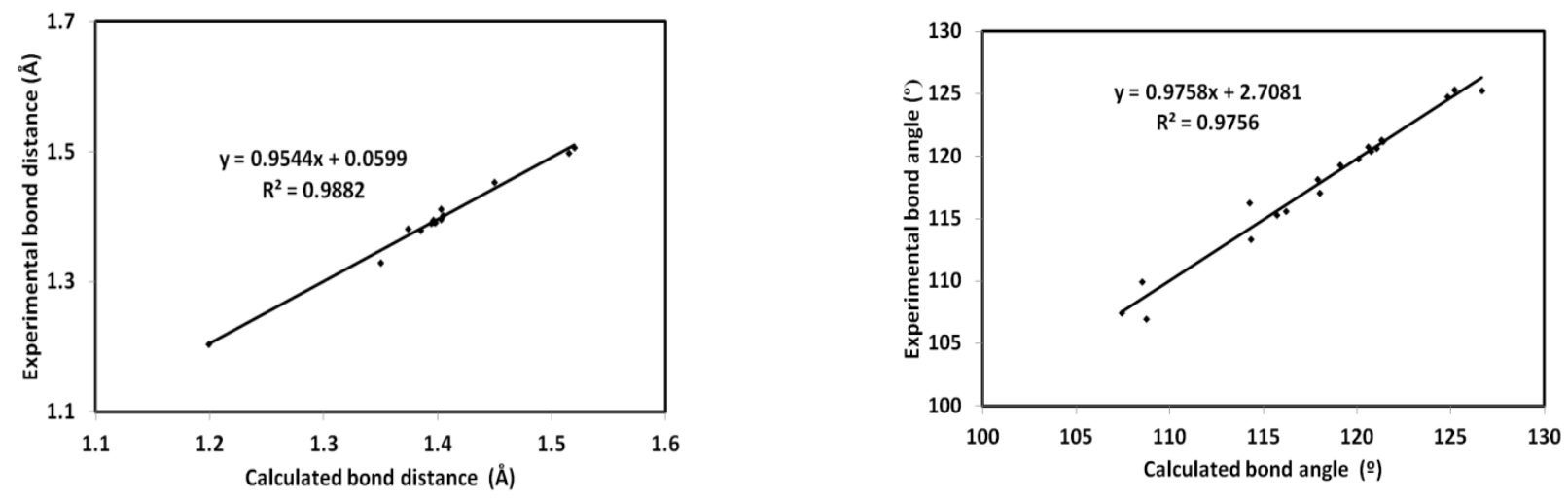

Figure 8. Correlations between the optimized and experimental geometric parameters.

Natural population analyses were performed and the results are shown in Figure 9 and Table S3 (Supplementary Materials). Generally, the O, N, and the majority of C atoms are electronegative. The oxygen sites have natural charges in the range from -0.5257 to $-0.5748 \mathrm{e}$, while the amino group $\mathrm{N}$-site has a natural charge of $-0.7827 \mathrm{e}$. In addition, the most negative $\mathrm{C}$-site is the methyl carbon $(-0.5847 \mathrm{e})$. In contrast, the carbonyl carbon has the highest positive natural charge of $0.8225 \mathrm{e}$. Moreover, all hydrogen atoms are positively charged, where the $\mathrm{NH}_{2}$ protons are the most positively hydrogen sites $(0.3592-0.3596 \mathrm{e})$. Presentation of electron density along with the map of electrostatic potential (MEP) is shown in the left part of Figure 10. The net dipole moment is calculated to be 3.0327 D, indicating polar molecule (Figure 10). 


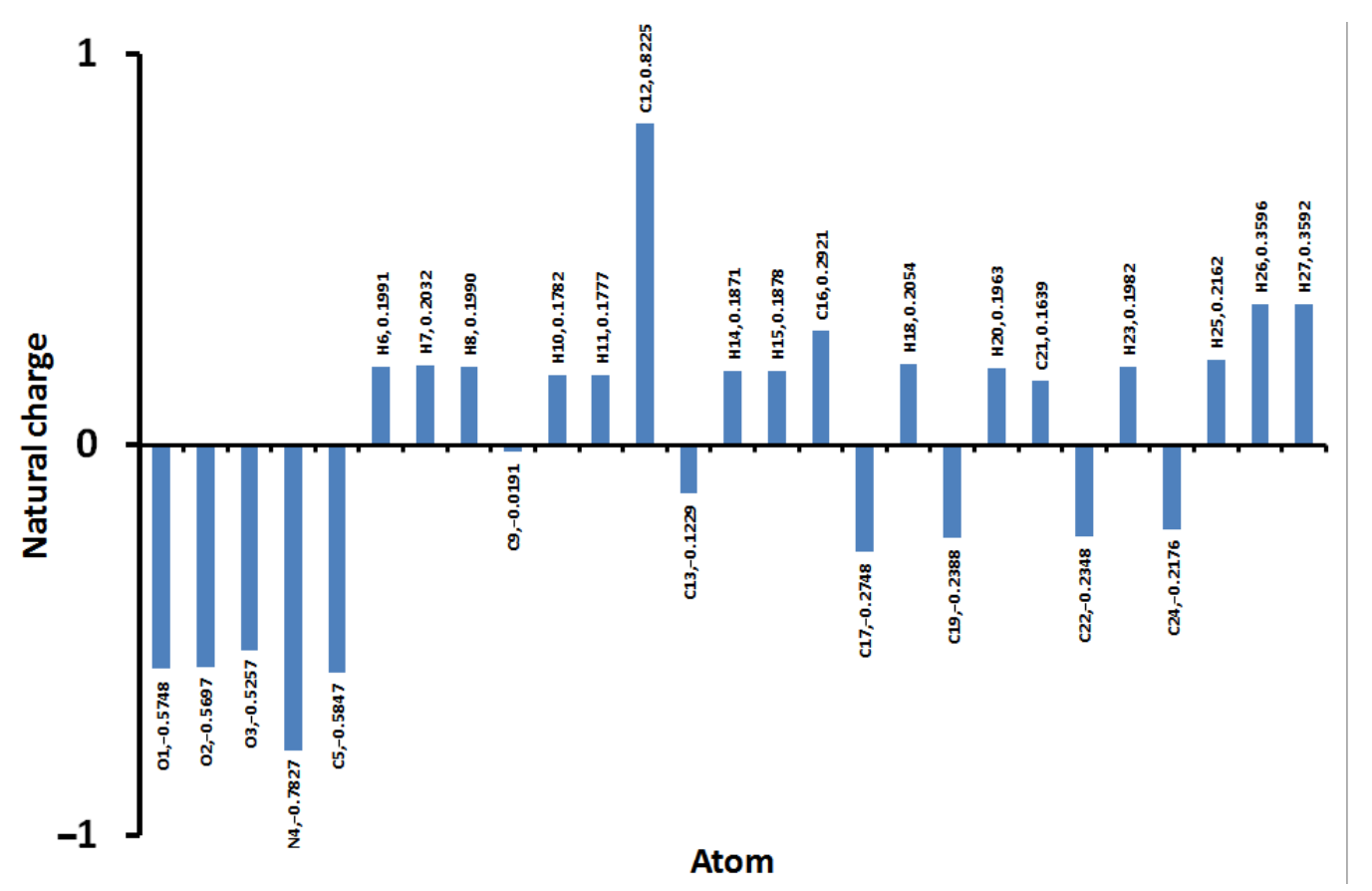

Figure 9. Natural atomic charge in 4 .
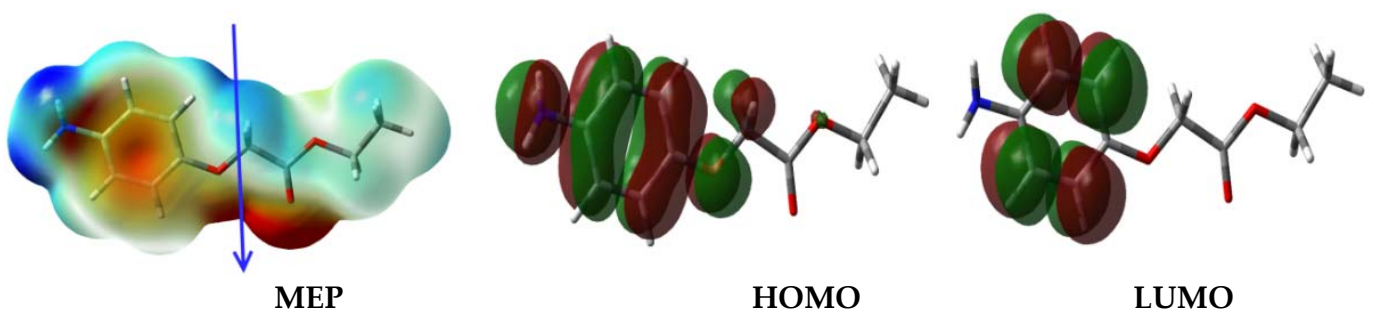

Figure 10. The MEP, HOMO, and LUMO of 4.

Among electronic parameters that have significant role in the molecular reactivity of compounds are the HOMO and LUMO levels and their energies (Figure 10). The HOMO and LUMO levels are generally distributed over the aryl group aromatic $\pi$ system, indicating $\mathrm{HOMO} \rightarrow \mathrm{LUMO}$ excitation based on $\pi-\pi^{*}$ transition. The energies of HOMO and LUMO are calculated to be -5.2648 and $-0.2876 \mathrm{eV}$, respectively. Hence, the $\mathrm{HOMO} \rightarrow \mathrm{LUMO}$ excitation required $4.9808 \mathrm{eV}$. Based on these electronic descriptors, the reactivity indices [22-28] such as ionization potential (I), electron affinity (A), hardness $(\eta)$, electrophilicity index $(\omega)$, and chemical potential $(\mu)$ are calculated to be $5.2684,0.2876$, $4.9808,0.7747$, and $-2.7780 \mathrm{eV}$, respectively.

In addition, the UV/Vis electronic spectra of 4 were calculated and the results were used to assign the experimental UV/Vis spectra (Figure 11). Obviously, two spectral bands were detected experimentally at 299 and $234 \mathrm{~nm}$. Moreover, the TD-DFT results revealed two spectral bands at 286 and $226 \mathrm{~nm}$, respectively. The oscillator strength values (f) of these bands are 0.068 and 0.294 , respectively. The calculated band at $286 \mathrm{~nm}$ was assigned to $\mathrm{HOMO} \rightarrow \mathrm{LUMO}(95 \%)$ excitation, while the shorter wavelength band was assigned to $\mathrm{HOMO} \rightarrow \mathrm{LUMO}+2(86 \%)$ transition. Both bands are mainly $\pi-\pi$ excitation, as indicated from the presentation of the MOs included in these transitions (Figure 12). 

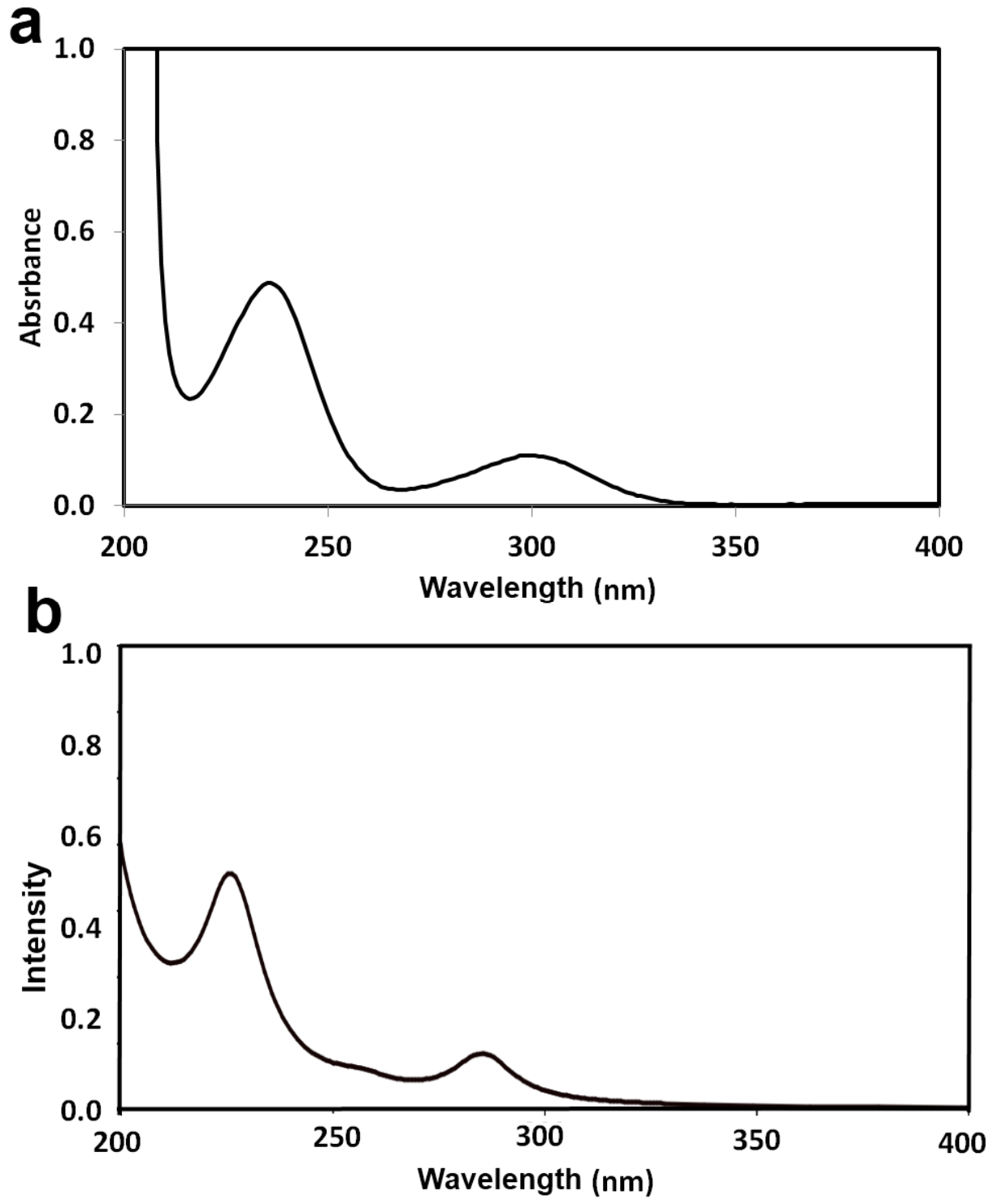

Figure 11. The experimental (a) and calculated (b) UV/Vis spectra of 4.

\subsection{NBO Analysis}

It is well known that the electron delocalization processes play an important role in the stability of molecular systems. In this regard, we investigated these electron delocalization processes using NBO calculations [29,30]. The compound is stabilized by different $\pi \rightarrow \pi^{*}$, $\mathrm{n} \rightarrow \sigma^{*}$, and $\mathrm{n} \rightarrow \pi^{*}$ electron delocalization processes. The stabilization energies $\left(\mathrm{E}^{(2)}\right)$ of the $\pi \rightarrow \pi^{*}$ electron delocalization processes (EDP) are in the range of $18.22-20.66 \mathrm{kcal} / \mathrm{mol}$. The $\mathrm{LP}(2) \mathrm{O} 1 \rightarrow \mathrm{BD}^{*}(2) \mathrm{O} 2-\mathrm{C} 12(45.95 \mathrm{kcal} / \mathrm{mol}) \mathrm{n} \rightarrow \pi^{*}$ electron delocalization process from the second lone pair NBO $(\mathrm{LP}(2) \mathrm{O})$ of oxygen has higher interaction energies $\left(\mathrm{E}^{(2)}\right)$ than the corresponding $\mathrm{LP}(1) \mathrm{O} 1 \rightarrow \mathrm{BD}^{*}(1) \mathrm{O} 2-\mathrm{C} 12(6.69 \mathrm{kcal} / \mathrm{mol}) \mathrm{n} \rightarrow \sigma^{*}$ EDP from the first lone pair NBO (LP(1)O). Detailed electron delocalization processes that stabilize the structure of $4 \mathrm{via}$ conjugation effect are listed in Table 4. 


\section{LUMO}

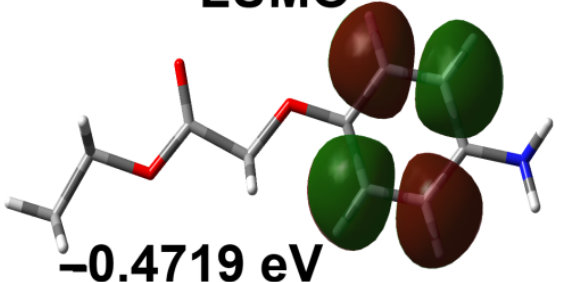

$-0.4719 \mathrm{eV}$

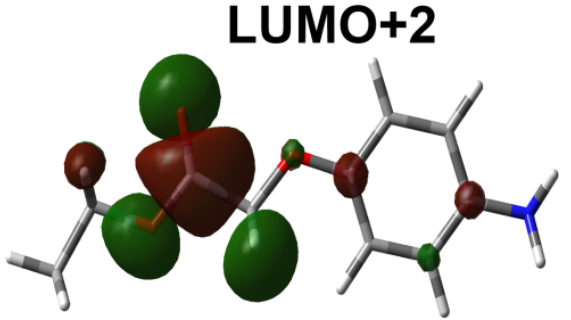

$+0.4044 \mathrm{eV}$

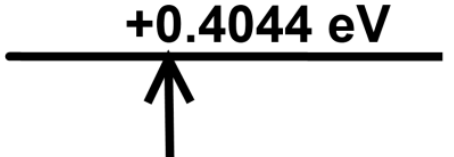

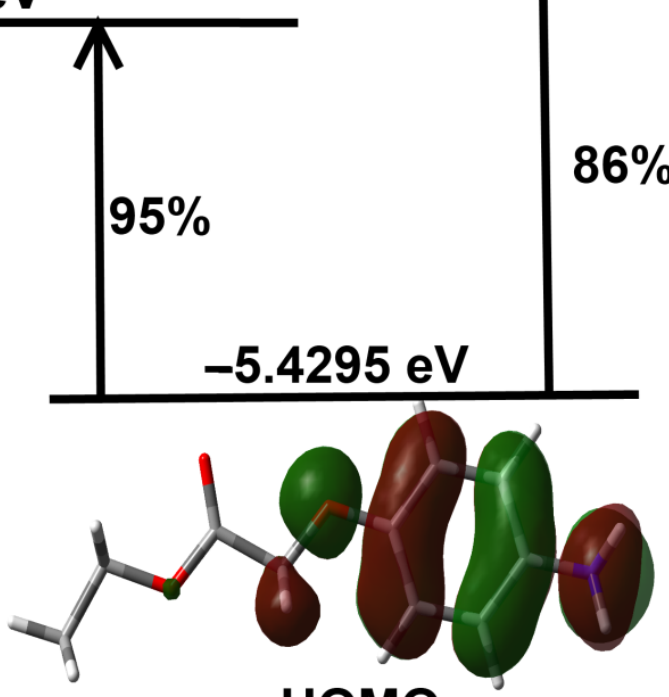

HOMO

Figure 12. MOs contributed in the electronic absorption of 4 .

Table 4. NBO electron delocalizations in 4.

\begin{tabular}{|c|c|c|c|c|c|}
\hline$(\mathrm{NBO})_{\mathrm{i}}{ }^{\mathrm{a}}$ & $(\mathrm{NBO})_{j}{ }^{b}$ & $E^{(2)}$ & $(\mathrm{NBO})_{\mathrm{i}}{ }^{\mathrm{a}}$ & $(\mathrm{NBO})_{\mathrm{j}}{ }^{b}$ & $E^{(2)}$ \\
\hline BD(2)C19-C21 & $\mathrm{BD}^{*}(2) \mathrm{C} 16-\mathrm{C} 17$ & 20.60 & LP(1)O1 & $\mathrm{BD}^{*}(1) \mathrm{O} 2-\mathrm{C} 12$ & 6.69 \\
\hline BD(2)C19-C21 & $\mathrm{BD}^{*}(2) \mathrm{C} 22-\mathrm{C} 24$ & 18.37 & LP(2)O2 & BD*(1)O1-C12 & 32.42 \\
\hline $\mathrm{BD}(2) \mathrm{C} 16-\mathrm{C} 17$ & $\mathrm{BD}^{*}(2) \mathrm{C} 19-\mathrm{C} 21$ & 18.22 & $\mathrm{LP}(2) \mathrm{O} 2$ & $\mathrm{BD}^{*}(1) \mathrm{C} 12-\mathrm{C} 13$ & 21.13 \\
\hline $\mathrm{BD}(2) \mathrm{C} 16-\mathrm{C} 17$ & $\mathrm{BD}^{*}(2) \mathrm{C} 22-\mathrm{C} 24$ & 19.13 & LP(1)O3 & $\mathrm{BD}^{*}(1) \mathrm{C} 16-\mathrm{C} 17$ & 6.87 \\
\hline $\mathrm{BD}(2) \mathrm{C} 22-\mathrm{C} 24$ & $\mathrm{BD}^{*}(2) \mathrm{C} 16-\mathrm{C} 17$ & 18.73 & LP(2)O1 & $\mathrm{BD}^{*}(2) \mathrm{O} 2-\mathrm{C} 12$ & 45.95 \\
\hline \multirow[t]{2}{*}{$\mathrm{BD}(2) \mathrm{C} 22-\mathrm{C} 24$} & $\mathrm{BD}^{*}(2) \mathrm{C} 19-\mathrm{C} 21$ & 19.80 & $\mathrm{LP}(2) \mathrm{O} 3$ & $\mathrm{BD}^{*}(2) \mathrm{C} 16-\mathrm{C} 17$ & 27.10 \\
\hline & & & LP(1)N4 & $\mathrm{BD}^{*}(2) \mathrm{C} 19-\mathrm{C} 21$ & 24.28 \\
\hline
\end{tabular}

${ }^{\mathrm{a}}$ Donor $\mathrm{NBO} ;{ }^{\mathrm{b}} \mathrm{BD}^{*}$ : acceptor $\mathrm{NBO} .{ }^{\mathrm{c}} \mathrm{E}^{(2)}$ : Second order perturbation energy.

\section{Conclusions}

A safe, low-cost, and rapid procedure was used for the synthesis of ethyl-2-(4-aminophenoxy) acetate (4) as a building synthon for novel dual hypoglycemic agents via selective and consecutive reduction of $p$-nitrophenoxy acetate using $\mathrm{NH}_{4} \mathrm{Cl} / \mathrm{Fe}$ protocols. The target synthon was obtained in good yield and its structure was confirmed using elemental analysis, NMR spectra, and X-ray diffraction of single crystal. The supramolecular structure of (4) is analyzed using Hirshfeld calculations. Its electronic and molecular structure aspects were investigated at the molecular level using DFT calculations. The TD-DFT calculation assigned the experimentally detected bands at 299 and $234 \mathrm{~nm}$, which mainly belong to $\pi-\pi$ transition. This work may provide an opportunity for the chemists to design new phenyl-urea derivatives as anti-diabetics agents activating dual-targets, GK and PPAR $\gamma$. 
Supplementary Materials: The following are available online at https:/ /www.mdpi.com/article/10.3390/ cryst12020227/s1, Table S1: The calculated geometric parameters of 4. Table S2: The calculated natural charges of 4 . References[31,32] are cited in the supplementary materials.

Author Contributions: Conceptualization, M.S.A. (Mohammed Salah Ayoup), A.B. and S.M.S.; methodology, M.S.A. (Mezna Saleh Altowyan) and A.B.; software, S.M.S. and M.H.; validation, M.S.A. (Mohammed Salah Ayoup) and M.M.F.I.; formal analysis, M.S.A. (Mohammed Salah Ayoup), M.M.F.I. and M.H.; investigation, M.S.A. (Mohammed Salah Ayoup); resources, M.S.A. (Mezna Saleh Altowyan) and A.B.; data curation, A.B. and S.M.S.; writing-original draft preparation, M.S.A., (Mezna Saleh Altowyan) A.B. and S.M.S.; writing-review and editing, A.B. and S.M.S.; visualization, A.B. and M.S.A. (Mohammed Salah Ayoup); supervision, A.B. and M.S.A. (Mohammed Salah Ayoup); project administration, M.S.A. (Mezna Saleh Altowyan); funding acquisition, M.S.A. (Mezna Saleh Altowyan). All authors have read and agreed to the published version of the manuscript.

Funding: Princess Nourah bint Abdulrahman University Researchers Supporting Project number (PNURSP2022R86), Princess Nourah bint Abdulrahman University, Riyadh, Saudi Arabia.

Institutional Review Board Statement: Not applicable.

Informed Consent Statement: Not applicable.

Data Availability Statement: Not applicable.

Acknowledgments: Princess Nourah bint Abdulrahman University Researchers Supporting Project number (PNURSP2022R86), Princess Nourah bint Abdulrahman University, Riyadh, Saudi Arabia.

Conflicts of Interest: The authors declare no conflict of interest.

\section{References}

1. Appel, S.J.; Wadas, T.M. Characterization of Type 2 Diabetes into Five Sub-Types. Curr. Res. Diabetes Obes. J. 2018, 8, 27-29. [CrossRef]

2. American Diabetes Association. Diagnosis and Classification of Diabetes Mellitus. Diabetes Care 2009, 32, S62-S67. [CrossRef] [PubMed]

3. Zhang, M.; Chen, L. Berberinein type 2 diabetes therapy: A new perspective for an old antidiarrheal drug? Acta Pharm. Sin. B 2012, 2, 378-386. [CrossRef]

4. Matschinsky, F.M.; Glaser, B.; Magnuson, M.A. Pancreatic beta-cell glucokinase: Closing the gap between theoretical concepts and experimental realities. Diabetes 1998, 47, 307-315. [CrossRef]

5. Moller, D.E. New drug targets for type2 diabetes and the metabolic syndrome. Nature 2001, 414, 821-827. [CrossRef]

6. Janani, C.; Kumari, B.R. PPAR gamma gene-A review. Diabetes Metab. Syndr. Clin. Res. Rev. 2015, 9, 46-50. [CrossRef]

7. Chen, D.; Guo, D.; Yan, Z.; Zhao, Y. Allenamide as a bioisostere of acrylamide in the design and synthesis of targeted covalent inhibitors. Med. Chem. Commun. 2018, 9, 244-253. [CrossRef]

8. Ghosh, A.K.; Samanta, I.; Mondal, A.; Liu, W.R. Covalent inhibition in drug discovery. ChemMedChem 2019, 14, 889-906. [CrossRef]

9. Serrano-Sterling, C.; Becerra, D.; Portilla, J.; Rojas, H.; Macías, M.; Castillo, J.C. Synthesis, biological evaluation and X-ray crystallographic analysis of novel (E)-2-cyano-3-(het) arylacrylamides as potential anticancer agents. J. Mol. Struct. 2021, 244, 130944. [CrossRef]

10. Rikagu Oxford Diffraction. CrysAlisPro; Agilent Technologies Inc.: Oxfordshire, UK, 2018.

11. Sheldrick, G.M. SHELXT-Integrated Space-Group and Crystal-Structure Determination. Acta Crystallogr. Sect. A Found. Adv. 2015, 71, 3-8. [CrossRef]

12. Sheldrick, G.M. Crystal Structure Refinement with SHELXL. Acta Crystallogr. Sect. C Struct. Chem. 2015, 71, 3-8. [CrossRef] [PubMed]

13. Hübschle, C.B.; Sheldrick, G.M.; Dittrich, B. ShelXle: A Qt graphical user interface for SHELXL. J. Appl. Crystallogr. 2011, 44, 1281-1284. [CrossRef] [PubMed]

14. Turner, M.J.; McKinnon, J.J.; Wolff, S.K.; Grimwood, D.J.; Spackman, P.R.; Jayatilaka, D.; Spackman, M.A. Crystal Explorer17; University of Western Australia: Crawley, WA, Australia, 2017; Available online: http:/ / hirshfeldsurface.net (accessed on 20 May 2017).

15. Frisch, M.J.; Trucks, G.W.; Schlegel, H.B.; Scuseria, G.E.; Robb, M.A.; Cheeseman, J.R.; Scalmani, G.; Barone, V.; Mennucci, B.; Petersson, G.A.; et al. GAUSSIAN 09; Revision A02; Gaussian Inc.: Wallingford, CT, USA, 2009.

16. GaussView; Dennington, R., II; Keith, T.; Millam, J. (Eds.) Semichem Inc.: Shawnee Mission, KS, USA, 2007 ; Version 4.1.

17. Reed, A.E.; Curtiss, L.A.; Weinhold, F. Intermolecular interactions from a natural bond orbital, donor-acceptor viewpoint. Chem. Rev. 1988, 88, 899-926. [CrossRef]

18. Zhang, L.; Tian, K.; Li, Y.; Lei, L.; Qin, A.; Zhang, L.; Song, H.; Huo, L.; Zhang, L.; Jin, X.; et al. Novel phenyl-urea derivatives as dual-target ligands that can activate both GK and PPAR $\gamma$. Acta Pharm. Sin. B 2012, 2, 588-597. [CrossRef] 
19. McKinnon, J.J.; Spackman, M.A.; Mitchell, A.S. Novel tools for visualizing and exploring intermolecular interactions in molecular crystals. Acta Crystallogr. Sect. B Struct. Sci. 2004, 60, 627-668. [CrossRef] [PubMed]

20. McKinnon, J.J.; Jayatilaka, D.; Spackman, M.A. Towards quantitative analysis of intermolecular interactions with Hirshfeld surfaces. Chem. Commun. 2007, 37, 3814-3816. [CrossRef] [PubMed]

21. Spackman, M.A.; Jayatilaka, D. Hirshfeld surface analysis. CrystEngComm 2009, 11, 19-32. [CrossRef]

22. Foresman, J.B.; Frisch, E. Exploring Chemistry with Electronic Structure Methods, 2nd ed.; Gaussian: Pittsburgh, PA, USA, 1996.

23. Chang, R. Chemistry, 7th ed.; McGraw-Hill: New York, NY, USA, 2001.

24. Kosar, B.; Albayrak, C. Spectroscopic investigations and quantum chemical computational study of $(E)-4-$ methoxy-2-[( $p$ tolylimino) methyl] phenol. Spectrochim. Acta 2011, 78, 160-167. [CrossRef]

25. Koopmans, T.A. Ordering of wave functions and eigenenergies to the individual electrons of an atom. Physica 1933, 1, 104-113. [CrossRef]

26. Parr, R.G.; Yang, W. Density-Functional Theory of Atoms and Molecules; Oxford University Press: New York, NY, USA, 1989.

27. Parr, R.G.; Szentpaly, L.V.; Liu, S. Electrophilicity index. J. Am. Chem. Soc. 1999, 121, 1922-1924. [CrossRef]

28. Singh, R.N.; Kumar, A.; Tiwari, R.K.; Rawat, P.; Gupta, V.P. A combined experimental and quantum chemical (DFT and AIM) study on molecular structure, spectroscopic properties, NBO and multiple interaction analysis in a novel ethyl 4-[2-(carbamoyl) hydrazinylidene]-3, 5-dimethyl-1H-pyrrole-2-carboxylate and its dimer. J. Mol. Strut. 2013, 1035, 427-440. [CrossRef]

29. Joe, I.H.; Kostova, I.; Ravikumar, C.; Amalanathan, M.; CîntǎPînzaru, S. Theoretical and vibrational spectral investigation of sodium salt of acenocoumarol. J. Raman Spectrosc. 2009, 40, 1033-1038. [CrossRef]

30. Sebastian, S.; Sundaraganesan, N. The spectroscopic (FT-IR, FT-IR gas phase, FT-Raman and UV) and NBO analysis of 4Hydroxypiperidine by density functional method. Spectrochim. Acta Part A Mol. Biomol. Spectrosc. 2010, 75, 941-952. [CrossRef] [PubMed]

31. Marten, B.; Kim, K.; Cortis, C.; Friesner, R.A.; Murphy, R.B.; Ringnalda, M.N.; Sitkoff, D.; Honig, B. New Model for Calculation of Solvation Free Energies: Correction of Self-Consistent Reaction Field Continuum Dielectric Theory for Short-Range HydrogenBonding Effects. J. Phys. Chem. 1996, 100, 11775-11788.

32. Tannor, D.J.; Marten, B.; Murphy, R.; Friesner, R.A.; Sitkoff, D.; Nicholls, A.; Ringnalda, M.; Goddard, W.A.; Honig, B. Accurate first principles calculation of molecular charge distributions and solvation energies from ab initio quantum mechanics and continuum dielectric theory. J. Am. Chem. Soc. 1994, 116, 11875-11882. 